\title{
The Impact of Inpatient Boarding on ED Efficiency: A Discrete-Event Simulation Study
}

\author{
Aaron E. Bair • Wheyming T. Song • Yi-Chun Chen • \\ Beth A. Morris
}

Received: 16 March 2009/Accepted: 27 April 2009 / Published online: 15 May 2009

(C) The Author(s) 2009. This article is published with open access at Springerlink.com

\begin{abstract}
In this study, a discrete-event simulation approach was used to model Emergency Department's (ED) patient flow to investigate the effect of inpatient boarding on the ED efficiency in terms of the National Emergency Department Crowding Scale (NEDOCS) score and the rate of patients who leave without being seen (LWBS). The decision variable in this model was the boarder-releasedratio defined as the ratio of admitted patients whose boarding time is zero to all admitted patients. Our analysis shows that the Overcrowded ${ }^{+}$(a NEDOCS score over 100) ratio decreased from $88.4 \%$ to $50.4 \%$, and the rate of LWBS patients decreased from $10.8 \%$ to $8.4 \%$ when the boarder-released-ratio changed from $0 \%$ to $100 \%$. These results show that inpatient boarding significantly impacts both the NEDOCS score and the rate of LWBS patient and this analysis provides a quantification of the impact of boarding on emergency department patient crowding.
\end{abstract}

Keywords Emergency department overcrowding •

Discrete event simulation (DES) · National Emergency

Department Crowding Scale (NEDOCS) .

Leaving without being seen (LWBS)

A. E. Bair · B. A. Morris

Department of Emergency Medicine, University of California,

Davis, Medical Center,

Sacramento, CA, USA

W. T. Song $(\bowtie) \cdot$ Y.-C. Chen

Department of Industrial Engineering and Engineering

Management, National Tsing Hua University,

Hsinchu, Taiwan

e-mail: wheyming_song@yahoo.com

\section{Introduction}

Emergency Department (ED) crowding, a consequence of simultaneous increasing demand for health care and a deficit in available hospital beds and ED beds, has become an increasingly significant public health problem [1-4]. Numerous studies on ED crowding issues can be found in the fields of emergency medicine and public health [5-16]. ED crowding has been associated with various negative effects, including adverse patient outcomes (such as higher mortality, reduced quality of care and treatment delays), as well as detrimental financial effects [17].

Among the effects of ED crowding, those patients who elope or leave without being seen (LWBS) is a commonly used indicator of ED efficiency and has been considered an indication of a breakdown of the health care system [18-20]. Reducing the degree of ED crowding to retrieve LWBS patients can improve ED efficiency and raise confidence in communities.

Schneider et al. [21] stated that rapid transfer of admitted patients to inpatient beds would help alleviate the degree of ED crowding. However, they did not quantify the effects of such boarding policies. Therefore, in our study, we sought to investigate the effect of inpatient boarding on the ED's efficiency in terms of the National Emergency Department Crowding Scale (NEDOCS) score and the rate of patients who leave without being seen (LWBS) per day.

\section{Methods}

Study design and population

The discrete-event simulation (DES) method was used to develop a general ED flow model $[22,23]$. The boarder- 
released-ratio was used as the decision variable. And the NEDOCS score and the rate (proportion) of LWBS patients per day were used as the performance measures.

The DES model was based on a census of 26,984 patients who were treated in the ED of the University of California, Davis, Medical Center (UCDMC) from January through May, 2008. This hospital is a Level 1 academic trauma center in California with an annual ED census of approximately 60,000 .

Performance measurements

Two performance measures for assessing the ED quality used in the study are the NEDOCS score and the rate of LWBS patients in ED.

Average NEDOCS Score The NEDOCS score was originally developed by Weiss et al. [24] to assess the degree of ED crowding. The variables used in NEDOCS score are as follows:

- $L_{\mathrm{ED}}(t)$ : Total number of patients in the ED at time $t$, which is the number of patients in the ED occupying beds, including hallway beds,

- $b_{\mathrm{ED}}(t)$ : Number of ED beds at time $t$, which is the total number of available ED beds,

- $\quad L_{\text {admit }}(t)$ : Total number of admitted patients in the ED at time $t$, which is the number of ED patients waiting to be moved from the ED to the hospital,

- $b_{\mathrm{h}}(t)$ : Number of hospital beds, which is the total number of occupied and vacant inpatient beds,

- $W_{\mathrm{ED}}(t)$ : Waiting time from triage to ED bed placement for patients who did not arrive via ambulance, air, or law enforcement and were placed in ED beds at time $t$, that is, patients called in from the waiting room, placed in ED beds, and waiting to be seen by a physician,

- $\quad W_{\text {admit }}(t)$ : the longest boarding time of patients waiting for admission at time $t$,

- $L_{\mathrm{rp}}(t)$ : One-third of the total number of patients admitted to adult ICU beds who were present in the $\mathrm{ED}$ at the time of the ED census, rounded up to the next whole number.

All variables defined above are functions of time $t$. For simplicity, we may sometimes omit the argument $t$. It should be noted that the variables defined above are the same as those defined in the work of Weiss et al. [24] except for $W_{\mathrm{ED}}(t)$ and $L_{\mathrm{rp}}(t)$. Weiss et al. defined $W_{\mathrm{ED}}(t)$ as the waiting time from triage to $\mathrm{ED}$ bed placement for patients placed in ED beds at time $t$, and defined $L_{\mathrm{rp}}(t)$ as the number of ventilators in use in ED. The difference in terminology of these two variables was needed to accommodate our current data collecting methodology.

The NEDOCS score, which is also a function of time $t$, is as follows:

$$
\begin{aligned}
\operatorname{NEDOCS}(t)=-20 & +85.8\left(L_{\mathrm{ED}}(t) / b_{\mathrm{ED}}(t)\right)+600\left(L_{\mathrm{admit}}(t) / b_{\mathrm{h}}(t)\right) \\
& +5.64 W_{\mathrm{ED}}(t)+0.93 W_{\text {admit }}(t)+13.4 L_{\mathrm{rp}}(t) .
\end{aligned}
$$

In this study, the NEDOCS score was generated every $2 \mathrm{~h}$, for a total of 12 NEDOCS scores each day. The NEDOCS scores were then averaged, which is also denoted as NEDOCS without the argument $t$, as the performance measure:

$\mathrm{NEDOCS}=\sum_{t=0}^{11} \operatorname{NEDOCS}(t) / 12$

where $t=0$ (indicating midnight), $1,2, \ldots, 11$ (i.e., "11" indicates 10 P.M.).

The NEDOCS score has no upper bound, but can be divided into six levels related to ED crowding in UCDMC. Level 1 indicates the least crowding and Level 6 indicates the most crowding:

- Level 1: Not busy $(0 \leq$ NEDOCS $<20)$,

- Level 2: Busy $(20 \leq$ NEDOCS $<60)$,

- Level 3: Extremely busy but not overcrowded (60 $\leq$ NEDOCS $<100$ ),

- Level 4: Overcrowded $(100 \leq$ NEDOCS $<140)$,

- Level 5: Severely overcrowded $(140 \leq$ NEDOCS $<180)$,

- Level 6: Dangerously overcrowded ( $180 \leq$ NEDOCS).

Alternatively, the above six levels can be collapsed into two levels for simplicity:

- Overcrowded ${ }^{-}$, which unifies the first three levels (i.e., NEDOCS score $<100$ ); and

- Overcrowded $^{+}$, which unifies the last three levels (i.e., NEDOCS score $\geq 100$ ).

The relationship between the original six levels and the simplified two levels is illustrated in Fig. 1. The color tones

Fig. 1 The ED crowding levels

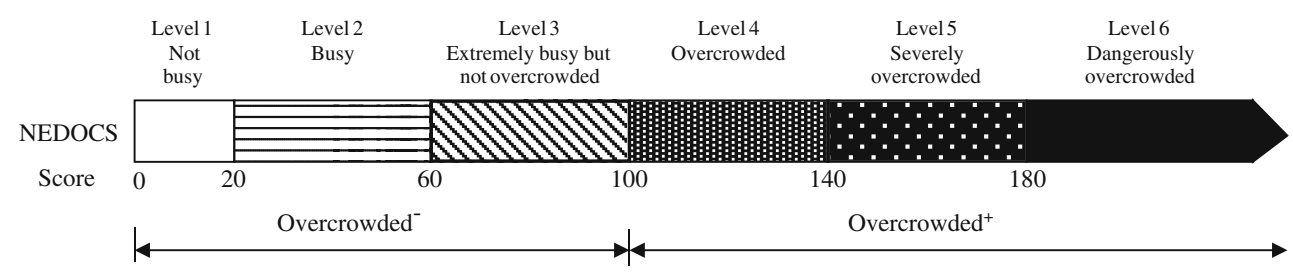


within the figure show the degrees of crowding severity and are used in Fig. 4b.

Rate of LWBS patients The other performance measure for ED quality is the rate of total LWBS patients, denoted as $R$-LWBS $\mathrm{T}$, which is defined as

$R-\mathrm{LWBS}_{\mathrm{T}}=\frac{\# \text { of the LWBS patients within a day }}{\# \text { of total arriving patients within a day }}$.

Analogously, we define $R$-LWBS and $R$-LWBS ${ }_{\mathrm{P}}$ to be the rates of LWBS patients for the adult unit and the pediatric unit, respectively, as follows.

$R-\mathrm{LWBS}_{\mathrm{A}}=\frac{\# \text { of the adult LWBS patients within a day }}{\# \text { of total adult arriving patients within a day }}$,

and

$R-\mathrm{LWBS}_{\mathrm{P}}=\frac{\# \text { of the pediatric LWBS patients within a day }}{\# \text { of total pediatric arriving patients within a day }}$.

The simulation model of the ED system

The flow for modeling UCDMC ED patients is illustrated in Fig. 2. In the figure, activities (i.e., events such as arrivals, treatments, or departures) are represented as circular nodes, and the sequences between two corresponding activities are represented as arrows. Dotted rectangles are used to denote the waiting times in the system, including waiting times before ED treatment (WTQueue 1), waiting times in the treatment area (WTtreatment), and boarding times in the ED waiting for an inpatient bed (WT-Queue 2).

In our model, patients initially arrive at the ED in the node "Arriving ED." Then in the node "Triage," each patient is classified as an adult (older than 16 years) or pediatric, and is further assigned to one of five triage categories: red (highest acuity), orange, yellow, green, and blue (least acuity). Each adult patient is sent to one of three adult treatment areas (Area 1, Area 3, and fast track), while the pediatric patients are sent exclusively to Area 2. The treatment areas for adult and pediatric patients are mutually independent units that do not share beds. Each patient is sent directly to the corresponding treatment area if there are vacant beds in the area in question, as shown in the node "Starting treatment"; otherwise, the patient waits in WT-Queue 1.

Priority for entering the corresponding treatment area is based on the patient's triage category and, when patients have the same category, they wait according to arrival time. Patients who wait in WT-Queue 1 may leave without being seen.

After treatment in the ED ("Finishing treatment"), some patients are discharged to go home ("Leaving after treatment"), while the others are admitted to the hospital
Fig. 2 Flow of ED patients' activities. $\left(k^{*}\right)$ indicates that there are $k$ random number streams generated in any simulation experiment

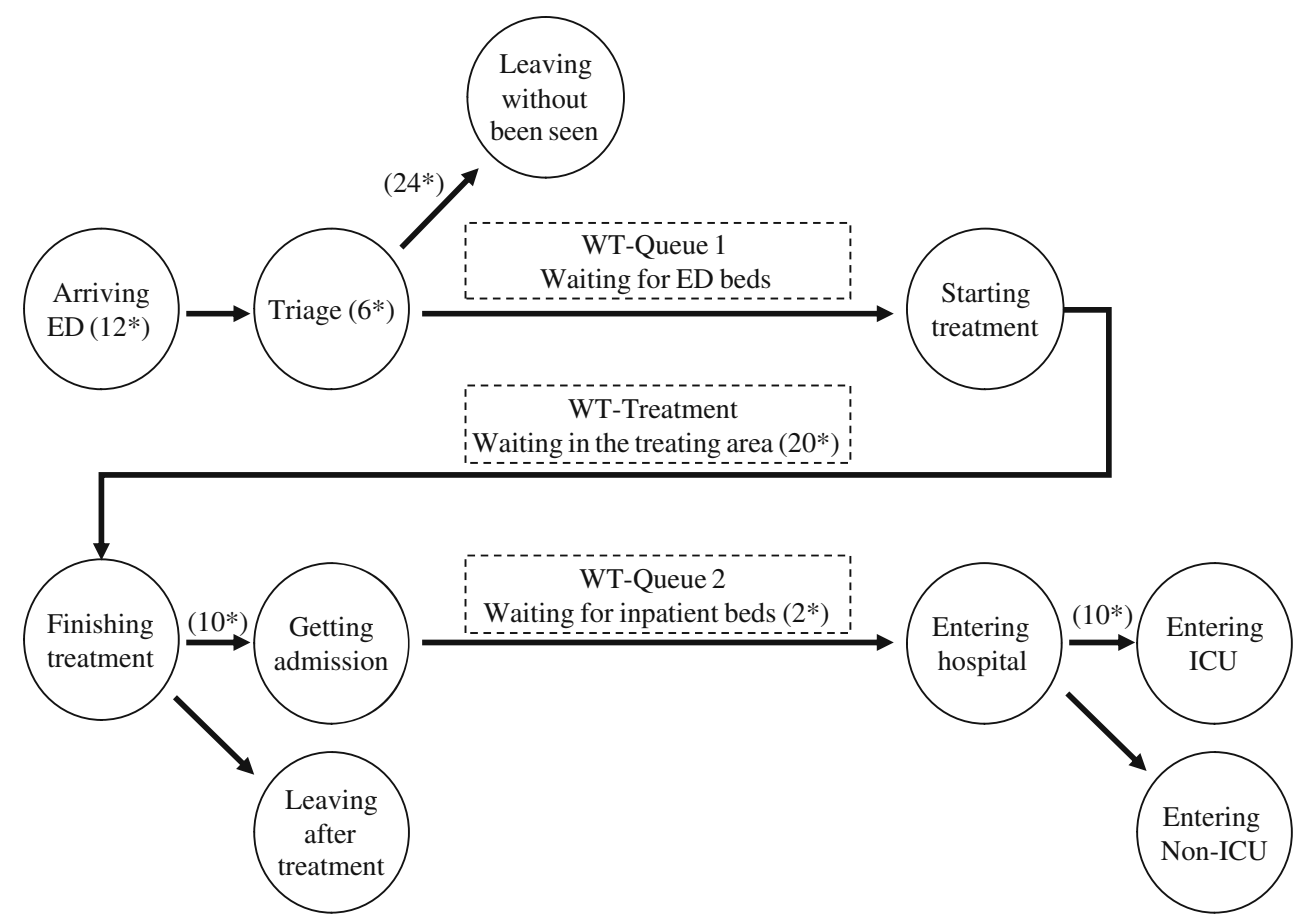


for further treatment ("Getting admission"). Admitted patients are called boarders if they have to wait in the ED (WT-Queue 2) for available hospital beds. The dispatching rule for boarders when they enter the hospital is first-infirst-out (FIFO). Finally, inpatients-those patients who enter the hospital ("Entering hospital") — are divided into ICU inpatients ("Entering ICU") and non-ICU patients ("Entering Non-ICU"), according to their medical needs.

The notation* listed in Fig. 2 indicates that one or more random number streams are needed in the simulation. The specific numbers of random number streams for each activity are listed in Table 3. For example, six random number streams are needed in the node "Triage": one is for classifying patient illness degree and adult/pediatric patients, and the others are for assigning the adult patients into different treatment areas.

\section{Simulation input modeling}

The simulation input modeling parameters include nonrandom parameters and random factors. Non-random parameters include the number of beds in the ED and the number of inpatient beds. Specifically, there are 42 ED beds in the UCDMC ED while there are 565 inpatient beds.

Eighty-four random number streams (RNS) were needed for each simulation run in our study, in order to generate the probability distributions and simple ratios. Descriptions of these RNS, the associated fitted distributions or ratios, the total numbers of RNS, and the referred tables providing specific parameters are given in Table 1. The indices $m, s$, $a$, and $t$ are used to denote age, illness degree, treatment area, and time; and $c, \alpha, \beta$ and $d$ are distribution parameters.
The fitted probability distributions are listed in the first four rows of Table 1. Row 1 lists the fitted patients' interarrival times at time $t$ as $c_{t} \operatorname{Beta}\left(\alpha_{t}, \beta_{t}\right)+d_{t}$ (a shifted beta distribution), where $t=0,1, \ldots, 11$ (i.e., every $2 \mathrm{~h}$ /day starting from midnight). Therefore, 12 RNS are needed to generate the probability distributions for patients' interarrival times. Row 2 lists the shifted beta distribution, $c_{m, s, a} \operatorname{Beta}\left(\alpha_{m, s, a}, \beta_{m, s, a}\right)+d_{m, s, a}$, used to fit patients' treatment times in each of four treatment areas for adult and pediatric patients with one of five illness degrees. There are 20 RNS needed (15 for adults and five for pediatrics; see Row 2).

It should be noted that the detailed internal procedures in the treatment area including preemption for patients with more acute illness are not included in the model because the complete treatment times are assumed to be accounted for in the overall processing times of these complicated activities.

The distributions of the boarding times for adult (Row 3) and pediatric patients (Row 4$)$ are fitted as 4,270Beta( 0.59 , $6.53)$ and $1,110 \mathrm{Beta}(0.84,4.32)$, respectively. Rows 5 to 10 list probabilities for patients' severity and age, adult LWBS patients, pediatric LWBS patients, adult patients entering different treatment areas, ED patients getting admission, and boarders sent to ICU. For example, Row 5 lists the $\mathrm{P}_{1}(m, s, t)$ values, which denotes the triage probability that each arriving patient is assigned to one of ten types, a combination of severity degree and patient age (adult or pediatric). As another example, Rows 6 and 7 list P(Adult, $t$ ) and $\mathrm{P}$ (Pediatric, $t$ ) values which denote the probabilities that the arriving patient leaves without being seen after triage, for adults and pediatric, respectively. The regressions $\mathrm{P}($ Adult, $t)=0.00109 \operatorname{NEDOCS}(t)-0.0250$ and P (Pediatric,

Table 1 Input random factors

\begin{tabular}{|c|c|c|c|c|}
\hline Distribution/ratios & Probability model/value & \# of random streams & Referred table & Row \\
\hline \multicolumn{5}{|l|}{ Distribution } \\
\hline Patient inter-arrival time & $c_{t} \operatorname{Beta}\left(\alpha_{t}, \beta_{t}\right)+d_{t}$ & 12 & Table 3 & 1 \\
\hline Treatment time & $c_{m, s, a} \operatorname{Beta}\left(\alpha_{m, s, a}, \beta_{m, s, a}\right)+d_{m, s, a}$ & 10 & Table 4 & 2 \\
\hline \multirow[t]{2}{*}{ Boarding time } & Adult: $4270 \operatorname{Beta}(0.59,6.53)+1$ & 1 & & 3 \\
\hline & Pediatric: $1110 \operatorname{Beta}(0.84,4.32)+3$ & 1 & & 4 \\
\hline \multicolumn{5}{|l|}{ Ratios } \\
\hline Patients' severity and age & $\mathrm{P}(m, s, t)$ & 1 & Table 5 & 5 \\
\hline $\mathrm{LWBS}_{\mathrm{A}}$ & $\mathrm{P}($ Adult,$t)=0.00109 \mathrm{NEDOCS}(t)-0.0250$ & 12 & & 6 \\
\hline $\mathrm{LWBS}_{\mathrm{P}}$ & $\mathrm{P}($ Pediatric, $t)=0.000420 \mathrm{NEDOCS}(t)+0.0082$ & 12 & & 7 \\
\hline Adult entering different areas & $\mathrm{P}(s, a)$ & 5 & Table 6 & 8 \\
\hline Patients getting admission & $\mathrm{P}(m, s)$ & 10 & Table 7 & 9 \\
\hline Boarders were sent to ICU & $\mathrm{P}(m, s)$ & 10 & Table 7 & 10 \\
\hline
\end{tabular}

Total numbers of random number streams is 84

$m$ : adult, pediatric; $s$ : Red, Orange, Yellow, Green, Blue; $a$ : Area 1, Area 2, Area 3, Fast Track; 
$t)=0.000420 \mathrm{NEDOCS}(t)+0.0082$ were constructed in Weiss et al. [13] to denote the relationships between the departure probabilities and the real-time degree of ED crowding.

\section{Verification and validation of the model}

Model validation is carried out to ensure that the proposed simulation model properly mimics the actual system. Model verification is practiced to check that, within its domain of applicability, the proposed simulation model possesses a satisfactory range of accuracy consistent with the intended application of the model [25]. Specifically, 1,000 replications of the 152-day period of simulation were implemented, and the averages of several primary indicators were compared to actual average values during the 152-day period from January 1 through May 31, 2008. The results, in terms of the average number of patients per day and the average waiting times, are shown in Table 2.

Regarding the average number of patients, including the average number of arriving patients and LWBS patients per day, we have found that the model underestimated the number of arriving adult patients by $2.3 \%$ and overestimated the number of arriving pediatric patients by $7.5 \%$. For LWBS patients, the model underestimated adult LWBS patients by $7.9 \%$ and underestimated pediatric LWBS patients by $8.3 \%$. The right-hand half of the table displays the average activity times (in minutes), including waiting time in the waiting room after triage, treatment time in the treatment area, and boarding time. The model underestimated waiting time by $7.1 \%$, overestimated treatment time by $11.3 \%$, and overestimated boarding time by $5.0 \%$. The final column displays the average NEDOCS score at 7:00 P.M., and the model underestimated the score by $8.2 \%$. In summary, all differences between the actual and modeled results except for waiting time in treatment were less than $10 \%$. We conclude that the proposed simulation model is valid.

\section{Decision variables}

In our simulation model, the decision variable was the boarder-released-ratio, denoted by $r$, which was the proportion of admitted patients who were sent to an assigned inpatient bed after their ED treatments were finished. That is,

$$
\begin{aligned}
r= & \left(\frac{\# \text { of admitted patients who were moved to inpatient beds }}{\text { total } \# \text { of admitted patients }}\right) \\
& \times 100 \% .
\end{aligned}
$$

The relationship among the ED, boarding time, $r$, and the hospital is shown in Fig. 3.

When implementing the simulation experiments, we generated a Uniform $(0,1)$ random variable $U$ and then compared $u$ with $r$ for each admitted patient. If $u<r$, then the patient would be sent to an inpatient bed. Otherwise, the patient would stay in the ED, as a boarder, waiting for an available hospital bed.

Common random numbers

We used Common random numbers (CRN), which is a variance reduction technique $[26,27]$, to minimize the sampling in our study. We executed 10,000 replications of the simulation experiments for each of the 11 scenarios. One replication generated one estimated NEDOCS score. Therefore, there were 10,000 estimated values of the NEDOCS estimate. Based on this data, we can obtain the final estimates and the standard error of NEDOCS. To utilize CRN, we relied on the same random stream set $\bar{R}$ for all 11 values of $r$ in a replication. As shown in Column 2 in Table 1 , there are $n$ random streams in a set; that is, $\bar{R}=\left\{R_{1}, R_{2}, \ldots, R_{n}\right\}$, where the total random number streams is $n=84$.

\section{Results}

The simulation results demonstrate the impact of the decision variable on the NEDOCS score, $R$-LWBS, $R$ $\mathrm{LWBS}_{\mathrm{A}}$, and $R$-LWBS . The results show that the value of the NEDOCS score has a significant impact on the four performance measures.

\begin{tabular}{|c|c|c|c|c|c|c|c|c|}
\hline & \multicolumn{4}{|c|}{ Average number of patients per day } & \multicolumn{4}{|c|}{ Average time (min) } \\
\hline & Adult arrival & Pediatric arrival & Adult LWBS & Pediatric LWBS & Waiting & Treating & Boarding & NEDOCS at 7:00P.M. \\
\hline True & 143.9 & 34.8 & 19.1 & 2.4 & 92.8 & 293.0 & 333.2 & 158.4 \\
\hline Fitted & 140.6 & 37.4 & 17.6 & 2.2 & 86.2 & 326.0 & 349.9 & 145.4 \\
\hline$\%$ error & $-2.3 \%$ & $7.5 \%$ & $-7.9 \%$ & $-8.3 \%$ & $-7.1 \%$ & $11.3 \%$ & $5.0 \%$ & $-8.2 \%$ \\
\hline
\end{tabular}

Table 2 Comparison between true and fitted data 


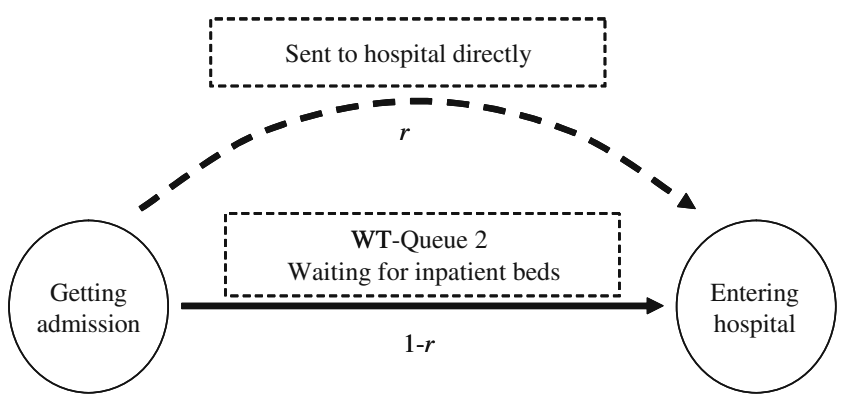

Fig. 3 The role of $r$

The effect of $r$ on the NEDOCS scores and levels

The effects of $r$ on the NEDOCS score, six-level NEDOCS, and two-level NEDOCS are illustrated in Figs. 4a-c, respectively. The error bars shown in Fig. 4a indicate 95\% confidence intervals (C.I.'s). As expected, the NEDOCS score decreases as $r$ increases. Consider two extreme cases: the NEDOCS scores are 135.6 and 109.2 when $r=0 \%$ and $r=100 \%$, respectively. That is, the NEDOCS scores decrease by $20 \%$ when $r$ increases from $0 \%$ to $100 \%$.

The proportions of the six-level or simplified two-level NEDOCS scores are illustrated in Figs. 4b, c. Figure 4b displays the significance of $r$ on the proportions of NEDOCS Levels 3, 4, 5, and 6. Specifically, it shows that as $r$ is increased from $0 \%$ to $100 \%$, the proportion of NEDOCS Level 6 (i.e., Dangerously overcrowded) decreases from $10.1 \%$ to $4.7 \%$, NEDOCS Level 5 (i.e., Severely crowded) decreases from $28.2 \%$ to $13.9 \%$, NEDOCS Level 4 (i.e., Overcrowded) decreases from $50.1 \%$ to $31.8 \%$, and NEDOCS Level 3 (i.e., Extremely busy, but not overcrowded) increases from $11.7 \%$ to $48.7 \%$.

Moreover, Fig. $4 \mathrm{c}$ shows that as $r$ increases from $0 \%$ to $100 \%$, the proportion of Overcrowded ${ }^{+}$decreases from $88.3 \%(10.1+28.2+50.1 \%)$ to $50.4 \%(4.7+13.9+31.8 \%)$, and the proportion of Overcrowded ${ }^{-}$increases from $11.7 \%$ to $49.6 \%$.

The effect of $r$ on the rate of LWBS patients

We investigated how the decision variable affects the rate of LWBS Patients. Define $R$-LWBS,$R$ - $\mathrm{LWBS}_{\mathrm{A}}$, and $R$-LWBS ${ }_{\mathrm{P}}$ to be LWBS for total patients, adult patients, and pediatric patients, respectively. The error bars in the three plots shown in Fig. 5a indicate C.I.'s for $R$-LWBS $R$-LWBS $\mathrm{A}_{\mathrm{A}}$, and $R$-LWBS $\mathrm{L}_{\mathrm{P}}$. The impacts of $r$ on $R$-LWBS, $R$-LWBS $\mathrm{A}_{\mathrm{A}}$, and $R$-LWBS $\mathrm{P}$ are significant. Specifically, as $r$ increases from $0 \%$ to $100 \%, R$-LWBS decreases from $11.86 \%$ to $9.16 \%, R$ - $\mathrm{LWBS}_{\mathrm{A}}$ decreases from $6.56 \%$ to $5.37 \%$, and $R$-LWBS ${ }_{\mathrm{T}}$ decreases from $10.81 \%$ to $8.42 \%$.

The percentage reduction of $R$-LWBS $\mathrm{A}, R-\mathrm{LWBS}_{\mathrm{P}}$, $R$-LWBS $\mathrm{T}_{\mathrm{T}}$ with respect to $r$ is shown in Fig. $5 \mathrm{~b}$. The two plots for $R$-LWBS $\mathrm{A}_{\mathrm{A}}$ and $R$-LWBS $\mathrm{T}$ in Fig. $5 \mathrm{~b}$ are nearly identical, showing negligible differences for any $r$. The differences among the three plots in Fig. $5 \mathrm{~b}$ are also negligible when $r \leq 20 \%$. When $r>20 \%$, the percentage reduction of $R$-LWBS for pediatrics is smaller than that for

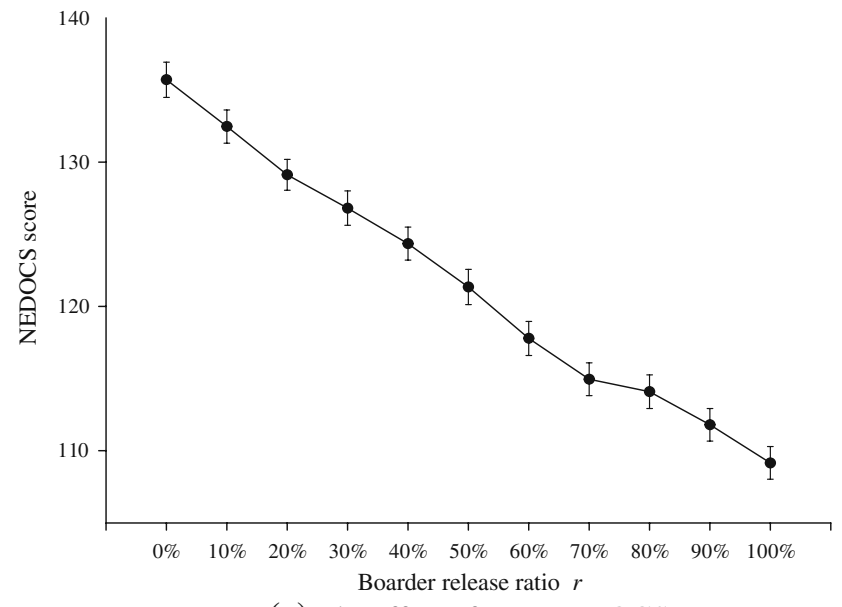

(a) The effect of $r$ on NEDOCS

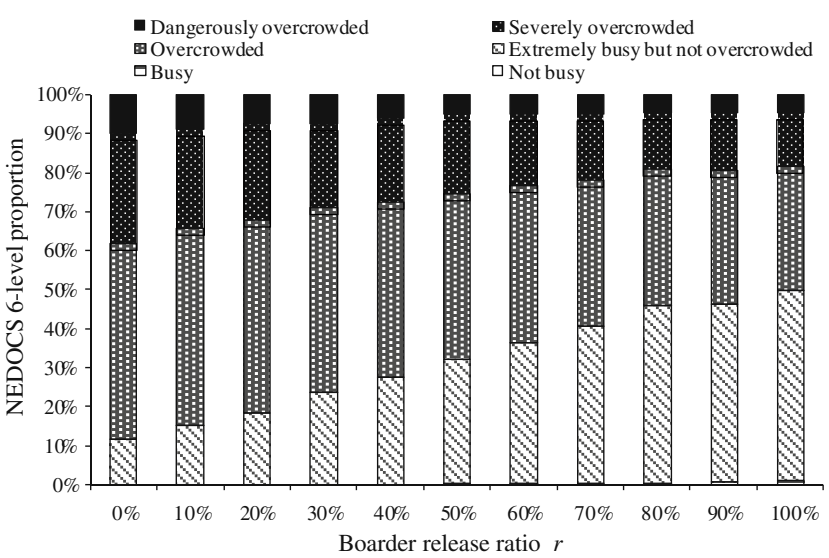

(b) $r$ vs. NEDOCS 6-level proportion

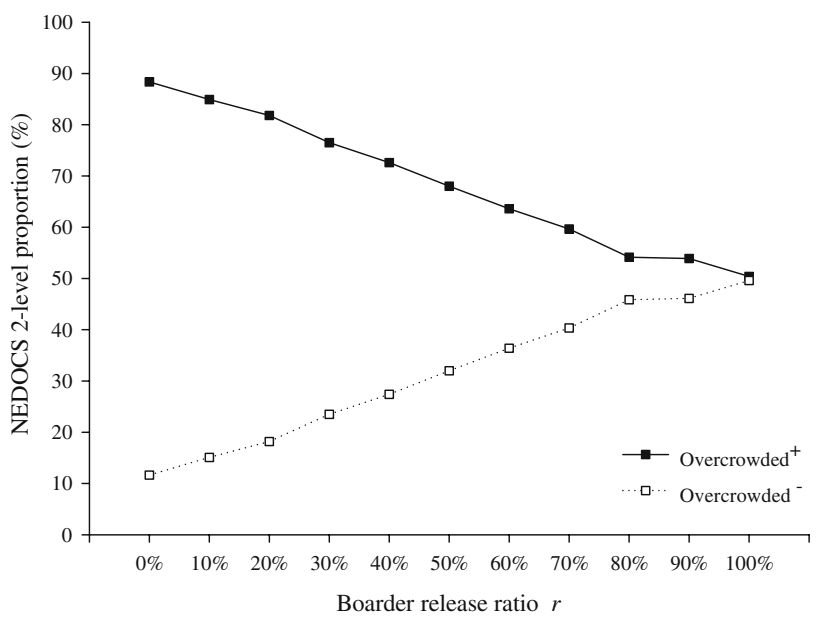

(c) $r$ vs. NEDOCS 2-level proportion

Fig. 4 The effect of $r$ on NEDOCS score 
Fig. 5 The effect of $r$ on $R$-LWBS

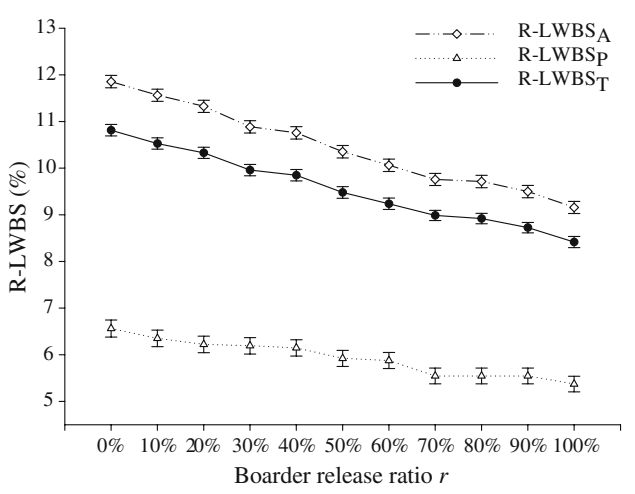

(a) The effect of $r$ on NEDOCS

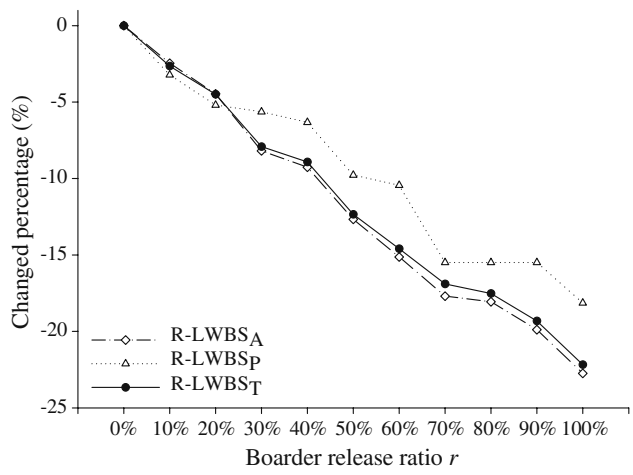

(b) $r$ vs. NEDOCS 6-level proportion
$R$-LWBS for adults. For example, the percentage reductions for $R-\mathrm{LWBS}_{\mathrm{P}}$ and $R-\mathrm{LWBS}_{\mathrm{A}}$ are $9.78 \%$ and $12.65 \%$, respectively, when $r \leq 50 \%$; and the percentage reductions for $R$-LWBS $\mathrm{P}_{\mathrm{P}}$ and $R-\mathrm{LWBS}_{\mathrm{A}}$ are $18.14 \%$ and $22.75 \%$, respectively, when $r \leq 100 \%$.

\section{Discussion}

ED crowding has become a nationwide public health issue and efforts to measure and manage this problem are ongoing. Commonly used measures for the degree of ED crowding include NEDOCS, the Real-time Emergency Analysis of Demand Indicators (READI) [28, 29], the Emergency Department Work Index (EDWIN) [30], the Emergency Department Crowding Scale (EDCS) [31, 32], and the Work Score [33]. We chose the NEDOCS score to measure the degree of ED crowding because it is effective and efficient; the NEDOCS score has better performance in terms of predictive capability [34] and discriminatory power [15, 35].

Similarly, we chose LWBS to measure the quality of patient care because of its effectiveness and efficiency. LWBS has been commonly used in many communities as the key indicator of the state of ED safety net functions [36]. Moreover, the regression relationship between NEDOCS and the number of LWBS patients for the UCDMC ED center was available [13].

Based on the simulation model, we demonstrated how the average number of arriving patients, boarders, LWBS patients, and the NEDOCS scores varied with respect to different times (hours) per day. Figure 6a shows that during 7:00-8:00 A.M., about 3.5 patients arrived in ED, the minimum number of arrivals for the day. The number of patients arriving in the ED increases from 3.5 to about 11 during 1:00-2:00 P.M., the peak time per day. Figure 6b shows that the number of LWBS also changes over time during a day. The patterns of Figure $6 a, b$ are similar during the morning, but the maximum LWBS occurres at about
4:00 P.M., $3 \mathrm{~h}$ later than the 1:00 P.M. peak for patient arrivals in Fig. 6a reached its maximum. The 3-h shift (from 1:00 to 4:00 P.M.) was supposed to be the average waiting time for LWBS patients in Queue 1. Figures 6c, d show that the patterns of the average numbers of boarders and the average NEDOCS scores were consistent in that both reached their maximum around midnight and their minimum around noon. Nevertheless, the 24 coverage widths of each C.I. (bar) for boarders were essentially the same, while those for average NEDOCS scores varied. Results in Figs. 6a through $\mathrm{d}$ provide useful information for ED management, for example to help determine when to transfer admitted patients to inpatient beds.

To investigate the effect of $r$, we increased the value of $r$ from $0 \%$ to $100 \%$ by increments of $10 \%$. The results show that when $r$ was larger than $30 \%$, the total number of LWBS and adult LWBS patients were larger than pediatric LWBS patients in reduced percentages, which means the outputs of the total LWBS patients and adult LWBS patients were more sensitive to the effect of inpatient boarding than pediatric LWBS patients.

Based on the simulation results of 10,000 days, there are 178.1 arriving patients and 11.4 boarders in average on any given day. By the results shown in Fig. 4a, if two additional inpatient beds would be available per day (i.e. $r=20 \%, 20 \%$ of the boarders are moved to inpatient beds), the NEDOCS score would decrease from 135.6 to 129.1 , and the proportion of Overcrowded ${ }^{+}$days would decrease from $88.4 \%$ to $81.8 \%$.

Similarly, if five additional inpatient beds would be made available per day (i.e., $r=50 \%, 50 \%$ of the are moved to inpatient beds), the NEDOCS score would decrease from 135.6 to 121.3, and the proportion of Overcrowded ${ }^{+}$days would decrease from $88.4 \%$ to $68 \%$.

In the most extreme case, if 11 additional inpatient beds would be made available per day, then all boarders would be accommodated (assuming a stable ED census). The NEDOCS score would then decrease from 135.6 to 109.2, and the proportion of Overcrowded ${ }^{+}$days would decrease from $88.35 \%$ to $50.4 \%$. 


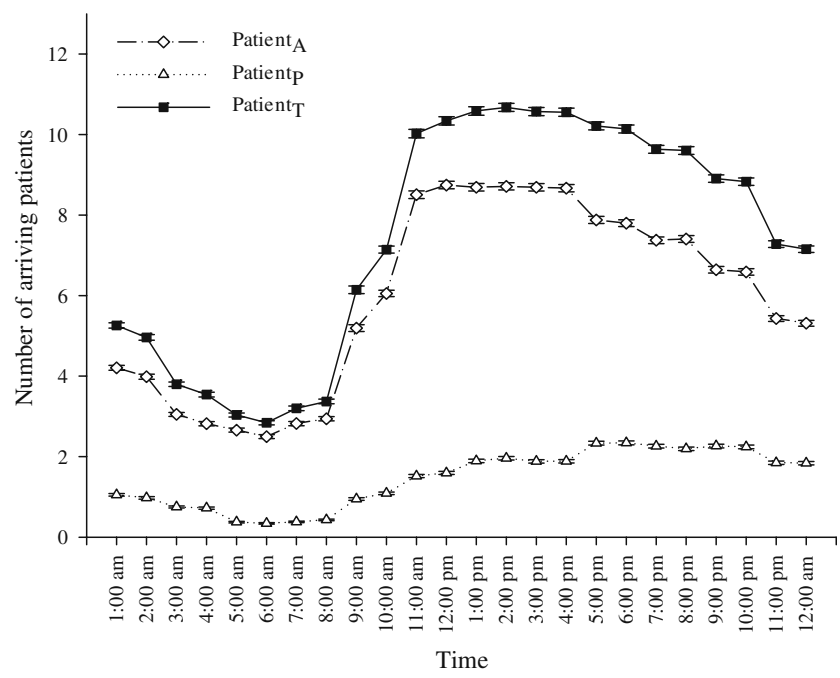

(a) Arriving patients for each hour

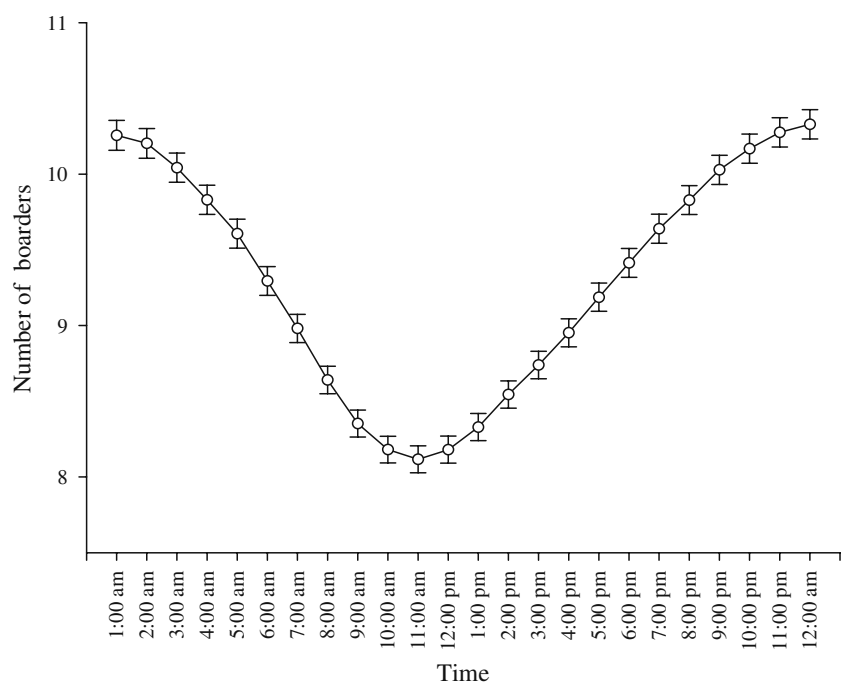

(c) Number of boarders for each hour

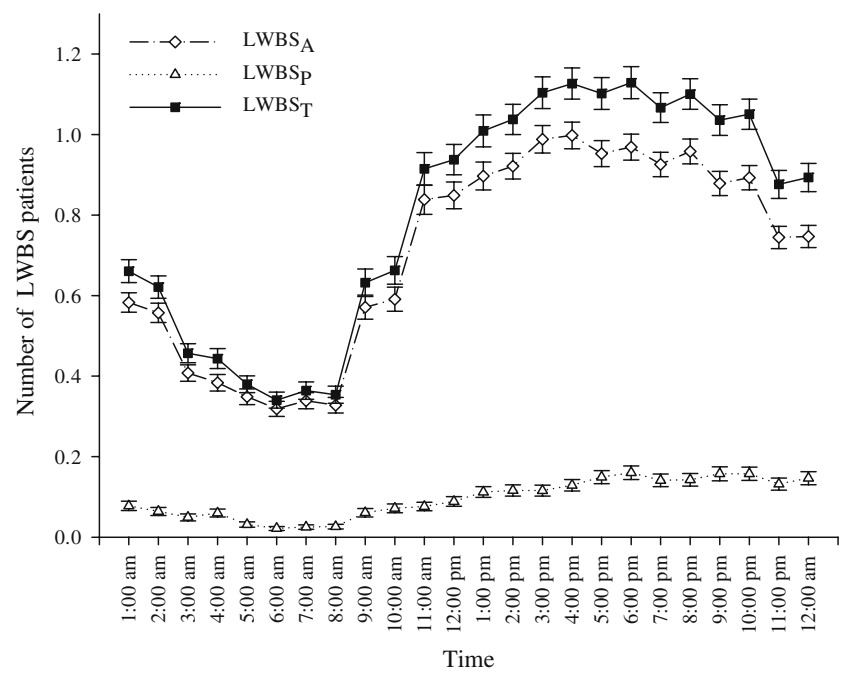

(b) Number of LWBS patients for each hour

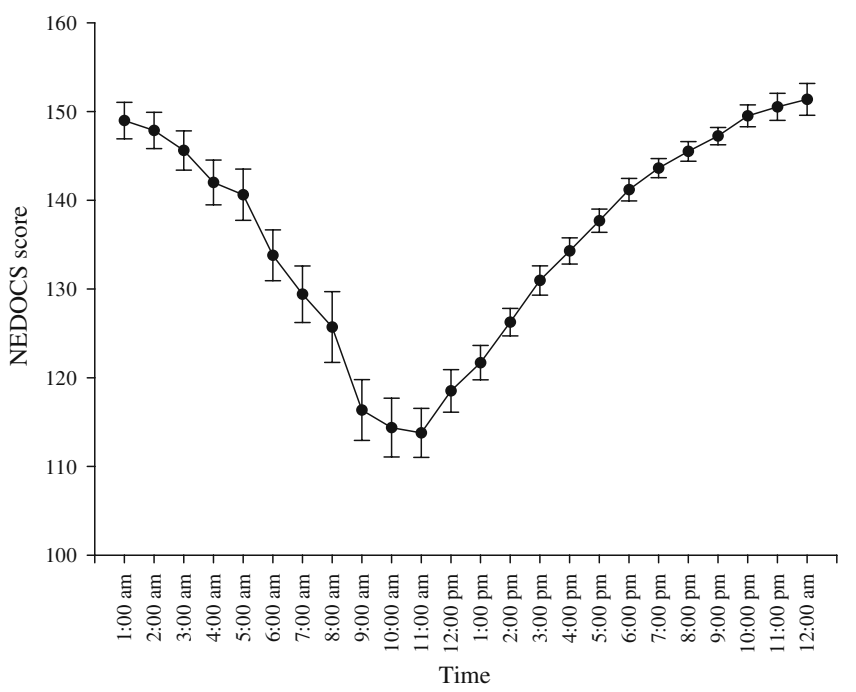

(d) NEDOCS score for each hour

Fig. 6 Related data for each hour

\section{Limitations}

Some limitations of our work should be mentioned and warrant future study. For instance, the simulation results were based on 5 months of data. A full year of data might yield more robust results (i.e., by revealing seasonal patterns). Additionally, we simplified certain complicated processes within the ED treatment areas. As such, the accuracy of the fitted distributions might be improved.

\section{Conclusion}

We constructed a discrete-event simulation model to investigate the effects of inpatient boarding on

ED crowding as measured by the NEDOCS score. The simulation results show that inpatient boarders have a significant impact on NEDOCS scores. We estimate that making two additional inpatient beds available per day would decrease the proportion of Overcrowded $^{+}$days from $88.4 \%$ to $81.8 \%$ and retrieve one additional LWBS patient per day. Under this boarding policy, 365 LWBS patients would be retrieved per year.

We conclude that our results provide useful information for the hospital in performing what-if analyses on how boarding policies affect the NEDCOS score. This research also provides a general framework that could be useful for other institutions that are contending with emergency department crowding. 


\section{Appendix}

Table 3 Distribution of inter-arrival time

\begin{tabular}{|c|c|}
\hline Time period & Distribution of interarrival time \\
\hline Midnight $\sim 2: 00$ A.M. & $75.03 \operatorname{beta}(0.84,4.36)+0.0137$ \\
\hline 2:00 A.M. $\sim 4: 00$ A.M. & $149 \operatorname{beta}(0.83,6.54)+0.0068$ \\
\hline 4:00 A.M. $\sim 6: 00$ A.M. & $126 \operatorname{beta}(0.82,4.08)+0.00806$ \\
\hline 6:00 A.M. $\sim 8: 00$ A.M. & $142 \operatorname{beta}(0.65,4.60)+0.00714$ \\
\hline 8:00 A.M. $\sim 10: 00$ A.M. & $84.02 \operatorname{beta}(0.77,7.03)+0.0122$ \\
\hline 10:00 A.M. $\sim$ Noon & 42.05beta $(1.26,7.91)+0.025$ \\
\hline Noon $\sim 2: 00$ P.M. & 58.04 beta $(1.36,12.68)+0.0179$ \\
\hline 2:00 P.M. $\sim 4: 00$ P.M. & 50.04 beta $(1.25,9.74)+0.0208$ \\
\hline 4:00 P.M. $\sim 6: 00$ P.M. & 37.06 beta $(1.10,5.80)+0.0286$ \\
\hline 6:00 P.M. $\sim 8: 00$ P.M. & 51.04 beta $(1.00,7.18)+0.0204$ \\
\hline 8:00 P.M. $\sim 10: 00 \quad$ P.M. & 59.04 beta $(1.19,9.09)+0.0175$ \\
\hline 10:00 P.M. $\sim$ Midnight & 71.03 beta $(1.13,8.38)+0.0145$ \\
\hline
\end{tabular}

Table 4 Distribution of treatment time

\begin{tabular}{lllll}
\hline Patient category & Area 1 & Area 2 & Area 3 & Fast track \\
\hline Red & $3620 \mathrm{beta}(1.57,16.30)+1$ & 3470beta $(1.36,18.03)+0.98$ & 2040beta $(1.67,8.78)+50$ & $695 \mathrm{beta}(1.55,3.41)$ \\
Orange & $2590 \mathrm{beta}(1.63,11.09)+20$ & $1980 \mathrm{beta}(1.59,13.6)+28$ & $5290 \mathrm{beta}(1.98,27.94)+30$ & $2840 \mathrm{beta}(0.71,8.57)+0.78$ \\
Yellow & $2720 \mathrm{beta}(1.74,12.29)+20.96$ & $8530 \mathrm{beta}(0.62,62.78)+1$ & $4300 \mathrm{beta}(1.81,19.61)+9.93$ & $1660 \mathrm{beta}(1.51,9.34)+1$ \\
Green & $1230 \mathrm{beta}(0.70,2.54)+26.55$ & $1900 \mathrm{beta}(1.36,17.26)$ & $1360 \mathrm{beta}(0.81,4.11)+19.99$ & $1680 \mathrm{beta}(1.08,8.98)+1$ \\
Blue & $776 \mathrm{beta}(0.54,2.96)$ & $194 \mathrm{beta}(1.53,1.89)+2.73$ & $786 \mathrm{beta}(0.59,2.86)$ & $571 \mathrm{beta}(0.85,3.24)+3.97$ \\
\hline
\end{tabular}

Table 5 Ratio of patients' severity and age (\%)

\begin{tabular}{|c|c|c|c|c|c|c|c|c|c|c|}
\hline & $\begin{array}{l}\text { Adult } \\
\text { red }\end{array}$ & $\begin{array}{l}\text { Adult } \\
\text { orange }\end{array}$ & $\begin{array}{l}\text { Adult } \\
\text { yellow }\end{array}$ & $\begin{array}{l}\text { Adult } \\
\text { green }\end{array}$ & $\begin{array}{l}\text { Adult } \\
\text { blue }\end{array}$ & $\begin{array}{l}\text { Pediatric } \\
\text { red }\end{array}$ & $\begin{array}{l}\text { Pediatric } \\
\text { orange }\end{array}$ & $\begin{array}{l}\text { Pediatric } \\
\text { yellow }\end{array}$ & $\begin{array}{l}\text { Pediatric } \\
\text { green }\end{array}$ & $\begin{array}{l}\text { Pediatric } \\
\text { blue }\end{array}$ \\
\hline Midnight $\sim$ 2:00 A.M. & 20.89 & 15.10 & 31.19 & 10.94 & 0.42 & 3.81 & 3.67 & 8.75 & 5.15 & 0.07 \\
\hline 2:00 A.M. $\sim 4: 00$ A.M. & 21.69 & 17.41 & 30.16 & 12.94 & 0.19 & 2.33 & 2.43 & 7.00 & 5.84 & 0.00 \\
\hline 4:00 A.M. $\sim 6: 00$ A.M. & 19.89 & 21.95 & 32.99 & 12.30 & 0.57 & 1.15 & 1.95 & 4.60 & 4.48 & 0.11 \\
\hline 6:00 A.M. $\sim 8: 00$ A.M. & 19.17 & 16.94 & 37.13 & 13.61 & 0.74 & 1.11 & 2.50 & 4.81 & 3.89 & 0.09 \\
\hline 8:00 A.M. $\sim 10: 00$ A.M. & 15.39 & 19.66 & 31.72 & 18.84 & 0.78 & 1.98 & 2.50 & 4.57 & 4.48 & 0.09 \\
\hline 10:00 A.M. $\sim$ Noon & 16.37 & 21.24 & 29.82 & 15.26 & 0.92 & 1.55 & 3.20 & 6.33 & 5.22 & 0.09 \\
\hline Noon 2:00 P.M. & 16.50 & 23.36 & 27.59 & 14.88 & 0.59 & 2.33 & 3.54 & 6.21 & 4.88 & 0.12 \\
\hline 2:00 P.M. $\sim 4: 00 \quad$ P.M. & 17.94 & 20.56 & 28.45 & 13.76 & 0.53 & 3.56 & 3.96 & 6.08 & 5.05 & 0.12 \\
\hline 4:00 P.M. $\sim 6: 00 \quad$ P.M. & 19.44 & 20.62 & 26.13 & 11.49 & 0.23 & 3.97 & 5.29 & 7.29 & 5.42 & 0.13 \\
\hline Midnight $\sim 2: 00$ A.M. & 17.66 & 20.38 & 27.79 & 9.93 & 0.14 & 3.76 & 4.00 & 9.62 & 6.69 & 0.03 \\
\hline 2:00 A.M. $\sim 4: 00$ A.M. & 16.52 & 18.18 & 29.05 & 10.45 & 0.19 & 3.37 & 4.62 & 10.19 & 7.35 & 0.08 \\
\hline 4:00 A.M. $\sim 6: 00$ A.M. & 17.48 & 16.44 & 28.92 & 11.43 & 0.29 & 2.57 & 4.57 & 10.96 & 7.15 & 0.19 \\
\hline
\end{tabular}


Table 6 Ratio of that adult ED patients entering different areas (\%)

\begin{tabular}{|c|c|c|c|c|c|}
\hline & Adult red & Adult orange & Adult yellow & Adult green & Adult blue \\
\hline Area 1 & 72.15 & 43.28 & 20.28 & 1.65 & 2.22 \\
\hline Area 3 & 27.23 & 52.26 & 41.43 & 4.58 & 4.44 \\
\hline Fast track & 0.63 & 4.47 & 38.29 & 93.77 & 93.33 \\
\hline
\end{tabular}

Table 7 Ratio of admitted patients and ICU patients (\%)

\begin{tabular}{lcccccccccc}
\hline & $\begin{array}{l}\text { Adult } \\
\text { red }\end{array}$ & $\begin{array}{l}\text { Adult } \\
\text { orange }\end{array}$ & $\begin{array}{l}\text { Adult } \\
\text { yellow }\end{array}$ & $\begin{array}{l}\text { Adult } \\
\text { green }\end{array}$ & $\begin{array}{l}\text { Adult } \\
\text { blue }\end{array}$ & $\begin{array}{l}\text { Pediatric } \\
\text { red }\end{array}$ & $\begin{array}{l}\text { Pediatric } \\
\text { orange }\end{array}$ & $\begin{array}{l}\text { Pediatric } \\
\text { yellow }\end{array}$ & $\begin{array}{l}\text { Pediatric } \\
\text { green }\end{array}$ & $\begin{array}{l}\text { Pediatric } \\
\text { blue }\end{array}$ \\
\hline $\begin{array}{l}\text { Ratio of the ED patients } \\
\text { getting admission }\end{array}$ & 49.97 & 43.73 & 20.69 & 5.23 & 1.28 & 41.37 & 32.79 & 11.45 & 3.47 \\
\begin{tabular}{l} 
Ratio of ICU patients \\
\hline
\end{tabular} & 25.05 & 8.84 & 5.69 & 2.56 & 0.00 & 3.55 & 0.74 & 0.22 & 0.00 & 0.00 \\
\hline
\end{tabular}

Open Access This article is distributed under the terms of the Creative Commons Attribution Noncommercial License which permits any noncommercial use, distribution, and reproduction in any medium, provided the original author(s) and source are credited.

\section{References}

1. Derlet, R. W., Overcrowding in emergency departments: Increased demand and decreased capacity. Ann. Emerg. Med. 39(4):430432, 2002.

2. Fatovich, D. M., Nagree, Y., and Sprivulis, P., Access block causes emergency department overcrowding and ambulance diversion in Perth, Western Australia. Emerg. Med. J. 22(5):351354, 2005.

3. Twanmoh, J. R., and Cunningham, G. P., When overcrowding paralyzes an emergency department. Manag. Care. 15(6):54-59, 2006.

4. Ackermann, R. J., Kemle, K. A., Vogel, R. L., and Griffin, R. C. $\mathrm{Jr}$, Emergency department use by nursing home residents. Ann. Emerg. Med. 31(6):749-757, 1998.

5. Asplin, B. R., Magid, D. J., Rhodes, K. V., Solberg, L. I., Lurie, N., and Camargo, C. A. Jr, A conceptual model of emergency department crowding. Ann. Emerg. Med. 42(2):173-180, 2003.

6. Derlet, R. W., and Richards, J. R., Overcrowding in the nation's emergency departments: complex causes and disturbing effects. Ann. Emerg. Med. 35(1):63-68, 2000.

7. Derlet, R. W., Richards, J. R., and Kravitz, R. L., Frequent overcrowding in U.S. emergency departments. Acad. Emerg. Med. 8(2):151-155, 2001.

8. Schull, M. J., Morrison, L. J., Vermeulen, M., and Redelmeier, D. A., Emergency department gridlock and out-of-hospital delays for cardiac patients. Acad. Emerg. Med. 10(7):709-716, 2003.

9. Schull, M. J., Morrison, L. J., Vermeulen, M., and Redelmeier, D. A., Emergency department overcrowding and ambulance transport delays for patients with chest pain. CMAJ. 168(3):277283, 2003.

10. Liu, S., Hobgood, C., and Brice, J. H., Impact of critical bed status on emergency department patient flow and overcrowding. Acad. Emerg. Med. 10(4):382-385, 2003.
11. Schull, M. J., Vermeulen, M., Slaughter, G., Morrison, L., and Daly, P., Emergency department crowding and thrombolysis delays in acute myocardial infarction. Ann. Emerg. Med. 44 (6):577-585, 2004.

12. Chen, E. H., Mills, A. M., Lee, B. Y., Robey, J. L., Zogby, K. E., Shofer, F. S., Reilly, P. M., and Hollander, J. E., The impact of a concurrent trauma alert evaluation on time to head computed tomography in patients with suspected stroke. Acad. Emerg. Med. 13(3):349-352, 2006.

13. Weiss, S. J., Ernst, A. A., Derlet, R., King, R., Bair, A. E., and Nick, T. G., Relationship between the National ED Overcrowding Scale and the number of patients who leave without being seen in an academic ED. Am. J. Emerg. Med. 23(3):288-294, 2005.

14. Rowe, B. H., Channan, P., Bullard, M., Blitz, S., Saunders, L. D., Rosychuk, R. J., Lari, H., Craig, W. R., and Holroyd, B. R., Characteristics of patients who leave emergency departments without being seen. Acad. Emerg. Med. 13(8):848-852, 2006.

15. Hoot, N. R., Zhou, C., Jones, I., and Aronsky, D., Measuring and forecasting emergency department crowding in real time. Ann. Emerg. Med. 49(6):747-755, 2007.

16. Vieth, T. L., and Rhodes, K. V., The effect of crowding on access and quality in an academic ED. Am. J. Emerg. Med. 24(7):787794, 2006.

17. Hoot, N. R., and Aronsky, D., Systematic review of emergency department crowding: causes, effects, and solutions. Ann. Emerg. Med. 52(2):126-136, 2008.

18. Baker, D. W., Stevens, C. D., and Brook, R. H., Patients who leave a public hospital emergency department without being seen by a physician. Causes and consequences. JAMA. 266(8):10851090, 1991.

19. Asaro, P. V., Lewis, L. M., and Boxerman, S. B., Emergency department overcrowding: analysis of the factors of renege rate. Acad. Emerg. Med. 14(2):157-162, 2007.

20. Hobbs, D., Kunzman, S. C., Tandberg, D., and Sklar, D., Hospital factors associated with emergency center patients leaving without being seen. Am. J. Emerg. Med. 18(7):767-772, 2000.

21. Schneider, S., Zwemer, F., Doniger, A., Dick, R., Czapranski, T., and Davis, E., Rochester, New York: a decade of emergency department overcrowding. Acad. Emerg. Med. 8(11):1044-1050, 2001.

22. Richardson, P., An introduction to system dynamics modeling. Productivity, New York, 1981. 
23. Banks, J., Carson, J. S., Nelson, B. L., and Nicol, D. M., Discrete-event system simulation, 3rd edition. Prentice-Hall, New Jersey, 2002.

24. Weiss, S. J., Derlet, R., Arndahl, J., Ernst, A. A., Richards, J., Fernández-Frackelton, M., Schwab, R., Stair, T. O., Vicellio, P., Levy, D., Brautigan, M., Johnson, A., and Nick, T. G., Estimating the degree of emergency department overcrowding in academic medical centers: results of the National ED Overcrowding Study (NEDOCS). Acad. Emerg. Med. 11(1):38-50, 2004.

25. Schlesinger, S., Crosbie, R. E., Innis, G. S., Lalwani, C. S., Loch, J., Sylvester, R. J., Wright, R. O., Kheir, N., and Bartos, D., Terminology for model credibility. Simulation. 32(3):103-104, 1979.

26. Law, A. M., Simulation modeling and analysis, 4th edition. McGraw-Hill, Boston, 2007.

27. Shechter, S. M., Schaefer, A. J., Braithwaite, R. S., and Roberts, M. S., Increasing the efficient of monte carlo cohort simulation with variance reduction techniques. Med. Decis. Mak. 26:550 $553,2006$.

28. Reeder, T. J., and Garrison, H. G., When the safety net is unsafe: real-time assessment of the overcrowded emergency department. Acad. Emerg. Med. 8(11):1070-1074, 2001.

29. Reeder, T. J., Burleson, D. L., and Garrison, H. G., The overcrowded emergency department: a comparison of staff perceptions. Acad. Emerg. Med. 10(10):1059-1064, 2003.

30. Bernstein, S. L., Verghese, V., Leung, W., Lunney, A. T., and Perez, I., Development and validation of a new index to measure emergency department crowding. Acad. Emerg. Med. 10(9):938942, 2003.

31. Asplin, B. R., Rhodes, K. V., Crain, L., and Camargo, C. A., Measuring emergency department crowding and hospital capacity. Acad. Emerg. Med. 9(5):366-367, 2002.

32. Asplin, B. R., Rhodes, K. V., Flottemesch, T. J., Wears, R., Camargo, C. A. Jr, Hwang, U., Richards, C. R., Tiffany, B., O'Keefe, S., and Bernstein, S., Is this emergency department crowded? A multicenter derivation and evaluation of an emergency department crowding scale (EDCS). Acad. Emerg. Med. 11:484, 2004.

33. Epstein, S. K., and Tian, L., Development of an emergency department work score to predict ambulance diversion. Acad. Emerg. Med. 13(4):421-426, 2006.

34. Jones, S. S., Allen, T. L., Flottemesch, T. J., and Welch, S. J., An independent evaluation of four quantitative emergency department crowding scales. Acad. Emerg. Med. 13(11):1204-1011, 2006.

35. Weiss, S. J., Ernst, A. A., and Nick, T. G., Comparison of the National Emergency Department Overcrowding Scale and the Emergency Department Work Index for quantifying emergency department crowding. Acad. Emerg. Med. 13(5):513-518, 2006.

36. Chan, T. C., Killeen, J. P., Kelly, D., and Guss, D. A., Impact of rapid entry and accelerated care at triage on reducing emergency department patient wait times, lengths of stay, and rate of left without being seen. Ann. Emerg. Med. 46(6):491-497, 2005. 